\title{
Patterns and early evolution of organ failure in the intensive care unit and their relation to outcome
}

\author{
Yasser Sakr ${ }^{1}$, Suzana M Lobo ${ }^{2}$, Rui P Moreno ${ }^{3}$, Herwig Gerlach ${ }^{4}$, V Marco Ranieri ${ }^{5}$, Argyris Michalopoulos ${ }^{6}$,
} Jean-Louis Vincent ${ }^{7^{*}}$ and the SOAP Investigators

\begin{abstract}
Introduction: Recognition of patterns of organ failure may be useful in characterizing the clinical course of critically ill patients. We investigated the patterns of early changes in organ dysfunction/failure in intensive care unit (ICU) patients and their relation to outcome.

Methods: Using the database from a large prospective European study, we studied 2,933 patients who had stayed more than 48 hours in the ICU and described patterns of organ failure and their relation to outcome. Patients were divided into three groups: patients without sepsis, patients in whom sepsis was diagnosed within the first 48 hours after ICU admission, and patients in whom sepsis developed more than 48 hours after admission. Organ dysfunction was assessed by using the sequential organ failure assessment (SOFA) score.

Results: A total of 2,110 patients (72\% of the study population) had organ failure at some point during their ICU stay. Patients who exhibited an improvement in organ function in the first 24 hours after admission to the ICU had lower ICU and hospital mortality rates compared with those who had unchanged or increased SOFA scores (12.4 and $18.4 \%$ versus 19.6 and $24.5 \%, P<0.05$, pairwise). As expected, organ failure was more common in sepsis than in nonsepsis patients. In patients with single-organ failure, in-hospital mortality was greater in sepsis than in nonsepsis patients. However, in patients with multiorgan failure, mortality rates were similar regardless of the presence of sepsis. Irrespective of the presence of sepsis, delta SOFA scores over the first 4 days in the ICU were higher in nonsurvivors than in survivors and decreased significantly over time in survivors.

Conclusions: Early changes in organ function are strongly related to outcome. In patients with single-organ failure, in-hospital mortality was higher in sepsis than in nonsepsis patients. However, in multiorgan failure, mortality rates were not influenced by the presence of sepsis.
\end{abstract}

\section{Introduction}

Multiple organ failure (MOF) is an evolving clinical syndrome triggered by various stimuli and may be a consequence of tissue hypoperfusion with cellular hypoxia, metabolic dysfunction, and impaired bioenergetic processes [1]. MOF is the main cause of morbidity and mortality in patients admitted to the intensive care unit (ICU) and is recognized as the final common pathway preceding death in critically ill patients [2-4]. Sepsis, a

\footnotetext{
* Correspondence: jvincen@ulb.ac.be

7 Department of Intensive Care, Erasme Hospital, Université Libre de Bruxelles, Brussels, Route de Lennik 808, 1070 Brussels, Belgium

Full list of author information is available at the end of the article
}

major public health problem, often progresses to MOF $[2,3]$, which is believed to increase markedly the risk of death in ICU patients $[2,3,5]$.

A need exists to evaluate organ function better over time in ICU patients. The Sequential Organ Failure Assessment (SOFA) score [6-8] was developed as a tool to describe quantitatively the time course of organ dysfunction $[9,10]$. Changes in SOFA score have been correlated with prognosis (delta SOFA and SOFA max) $[8,10]$ and are now widely used to assess the effects of therapeutic interventions $[11,12]$. The aim of our study was to investigate the relation between the patterns of early changes in organ function in the ICU and outcome

\section{Biomed Central}

(c) 2012 Sakr et al.; licensee BioMed Central Ltd. This is an open access article distributed under the terms of the Creative Commons Attribution License (http://creativecommons.org/licenses/by/2.0), which permits unrestricted use, distribution, and reproduction in any medium, provided the original work is properly cited. 
from critical illness. The study set up the hypothesis that recognition of early changes in organ function may characterize the clinical course of critically ill patients. Moreover, we explored the relative roles of sepsis and MOF in determining outcome in critically ill patients.

\section{Materials and methods}

This study is a subanalysis of the prospective, multicenter, observational study, the sepsis occurrence in acutely ill patients (SOAP) study, which was designed to create a database of ICU patients in European countries. Recruitment, data collection, and management are detailed elsewhere [2]; in brief, all patients older than 15 years admitted to the 198 participating centers (see the Acknowledgements for a list of participating countries and centers) between May 1 and May 15, 2002, were included. Patients who stayed in the ICU for less than 24 hours for routine postoperative observation were not included. Patients were followed up until death, hospital discharge, or for 60 days. Because the observational SOAP study did not require any deviation from routine medical practice, institutional review board approval was either waived or expedited in participating institutions, and informed consent was not required. As such, no supplementary review-board documents were needed for the current substudy.

Data were collected prospectively by using preprinted case-report forms. Data collection on admission included demographic data and comorbidities. Clinical and laboratory data for the simplified acute physiology score (SAPS) II [13] were reported as the worst value within 24 hours after admission. Microbiologic and clinical infections were reported daily, as well as the antibiotics administered. Organ function was evaluated on admission and daily thereafter, by using the SOFA score [6]. Data were encoded centrally in the organizing center by medical personnel (Department of Intensive Care, Erasme Hospital), and a number of quality control measures were carried out to assure consistency of the data and the quality of data entry [2]. All variables were defined $a$ priori, and definitions were available on an Internet-based website throughout the study period.

\section{Definitions}

Sepsis syndromes were defined according to consensus conference definitions [14]. Organ failure was defined as a SOFA score $>2$ for any of the six organs/systems evaluated, and MOF, as more than one failing organ [7]. An increase in the SOFA score of at least 1 point was considered as deterioration in organ function. SOFAmax was defined as the maximum SOFA score recorded during the ICU stay, and SOFAmean, as the mean value during the ICU stay. Individual organ failures during the ICU stay were defined according to the SOFAmax for the corresponding organ. Combinations of organ failures were considered independent of the time of onset of each organ failure. The delta SOFA ( $\triangle \mathrm{SOFA}$ ) was calculated as the difference between the SOFA score on a specific day and the score on the day of admission to the ICU [8].

\section{Statistical analysis}

For the purposes of this analysis, we excluded all patients who spent less than 48 hours in the ICU. To investigate the impact of sepsis on organ failure, patients were divided into three groups; Patients without sepsis, those in whom sepsis developed within 48 hours after ICU admission, and those in whom sepsis developed more than 48 hours after admission to the ICU.

Data were analyzed by using SPSS 13.0 for Windows (SPSS Inc., Chicago, IL, USA). Descriptive statistics were computed for all study variables. The Kolmogorov-Smirnov test was used to verify the normality of distribution of continuous variables. Nonparametric tests of comparison were used for variables evaluated as not normally distributed. Difference testing between groups was performed by using the two-tailed $t$ test, Mann-Whitney $U$ test, $\chi^{2}$ test, and Fisher Exact test, as appropriate, with a Bonferroni correction for multiple comparisons. Differences in SOFA scores between groups over time were assessed by using multifactorial analysis of variance (ANOVA).

Continuous data are presented as mean $\pm \mathrm{SD}$, and categoric data, as number (\%), unless otherwise indicated. All statistics were two-tailed, and a $P<0.05$ was considered to be statistically significant.

\section{Results}

\section{Characteristics of the study group}

Of the 3,147 patients included in the SOAP database, 2,933 patients stayed in the ICU for more than 48 hours (Table 1). The admission SOFA score for these patients was $5.0 \pm 3.7$; the maximum SOFA, $6.6 \pm 4.4$; and the mean SOFA, $5.0 \pm 3.7$. The median ICU length of stay was 3.4 (IQ, 2.0 to 7.6) days, and the median length of hospital stay, 16 (8 to 33 ) days. The overall ICU and hospital mortality rates were $16.6 \%$ and $21.9 \%$, respectively.

\section{Patterns of organ failure and their relation to outcome}

On admission to the ICU, 1,675 (57.1\%) patients had at least one organ failure; these patients had ICU and hospital mortality rates of $27.6 \%$ and $34.2 \%$, respectively. In total, 435 (15\%) patients developed organ failure in the ICU. The organ failures most commonly present on the day of admission to the ICU were of the cardiovascular (24\%) and respiratory (22\%) systems, whereas respiratory (43\%) and renal (36\%) organ failures were the most 
Table 1 Characteristics of the patients on ICU admission, lengths of ICU and hospital stays, and outcomes

\begin{tabular}{|c|c|}
\hline Number of patients & 2,933 \\
\hline Age, years, median $(\mathrm{IQ})^{\mathrm{a}}$ & $64(50-74)$ \\
\hline Sex, male/female, \% & $61.5 / 38.5$ \\
\hline \multicolumn{2}{|l|}{ Type of admission, n (\%) } \\
\hline Medical & $1,584(54.0)$ \\
\hline Surgical & $1,349(46.0)$ \\
\hline Elective & $766(26.1)$ \\
\hline Emergency & $583(19.9)$ \\
\hline \multicolumn{2}{|l|}{ ICU admission source, $\mathrm{n}(\%)^{\mathrm{b}}$} \\
\hline ER/ambulance & $818(27.9)$ \\
\hline Hospital floor & $726(24.8)$ \\
\hline OR/recovery room & $765(26.1)$ \\
\hline Other hospital & $332(11.3)$ \\
\hline \multicolumn{2}{|l|}{ Comorbidities, n (\%) } \\
\hline COPD & $322(11.0)$ \\
\hline Cancer & $299(10.2)$ \\
\hline Heart failure & $287(9.8)$ \\
\hline Diabetes & $208(7.1)$ \\
\hline Cirrhosis & $115(3.9)$ \\
\hline Hematologic cancer & $63(2.1)$ \\
\hline HIV/AIDS & $8(0.3)$ \\
\hline SAPS II score, mean \pm SD & $35.9 \pm 16.4$ \\
\hline SOFA score, mean \pm SD & $5.0 \pm 3.7$ \\
\hline$\underline{\text { Duration of ICU stay, days, median (IQ) }}$ & $3.4(2.0-7.6)$ \\
\hline Duration of hospital stay, days, median (IQ) & $16.0(8.0-33.0)$ \\
\hline$\overline{I C U}$ mortality, $\mathrm{n}(\%)^{\mathrm{C}}$ & $486(16.6)$ \\
\hline Hospital mortality, $\mathrm{n}(\%)^{d}$ & $642(21.9)$ \\
\hline
\end{tabular}

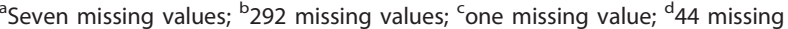
values.

prevalent during the ICU stay (Table 2). The combination of respiratory and cardiovascular organ failures was the most common on admission (9\%) and during the ICU stay (25\%).

Hospital mortality rates increased according to the severity of organ dysfunction/failure as assessed by the SOFA score (Figure 1) and according to the number of failing organs (Table 2). The highest hospital mortality rates were observed in patients with failure of the hepatic or coagulation systems, and in patients with combined coagulation and hepatic or coagulation and central nervous system (CNS) failure, mortality rates reached $70 \%$ to $80 \%$.

\section{Early changes in organ failure and outcome}

The time to achieve SOFAmax was longer in nonsurvivors than in survivors (2 (2 to 3 ) versus 1 ( 1 to 2 ) days; $P<0.001)$. Patients who exhibited an improvement or no change in organ function over the first 24 hours after admission to the ICU had lower ICU and hospital mortality rates compared with those whose scores increased (12.4 and 18.4\% versus 19.6 and $24.5 \%$; $P<$ 0.05 pairwise). Likewise, patients who exhibited an improvement or no change in organ function over the second day in the ICU had lower ICU and hospital mortality rates compared with those whose scores increased (13.8 and $20.7 \%$ versus 18.6 and $24.1 \%$; $P<0.05$ pairwise). Delta SOFA scores were higher and remained higher in nonsurvivors than in survivors over the first 4 days in the ICU; they decreased significantly over time in survivors (Figure 2).

\section{Impact of sepsis on incidence and outcome from organ failure}

In total, 1,144 (39\%) patients had sepsis at some point during the ICU stay, including 865 during the first 48 hours in the ICU and 279 after 48 hours. MOF occurred more frequently in patients with sepsis, irrespective of the time of onset (Table 3). During the ICU stay, renal failure was the most common organ failure in patients who never had sepsis, and respiratory failure was the most common in patients with sepsis.

ICU (24 and 28 versus $11 \% ; P<0.001$ each) and hospital mortality rates (33 and 33 versus $14 \% ; P<0.001$ each) were more than double in patients who had sepsis within or after 48 hours than in those who never had sepsis. Mortality from any type of organ failure was higher in patients with sepsis than in those who did not have sepsis, irrespective of the time of onset (Table 4). Hospital mortality rates in patients with single-organ failure during the ICU stay were higher in patients with sepsis than in those who never had sepsis (sepsis within 48 hours and sepsis after 48 hours versus no sepsis: hospital mortality, 16 and 13 versus 9\%, respectively; $P<$ 0.01 pairwise). However, patients with MOF had similar mortality rates regardless of whether they had sepsis (ICU mortality ranging from $23 \%$ to $76 \%$, and hospital mortality ranging from $32 \%$ to $89 \%$ ).

Delta SOFA scores over the first 4 days in the ICU were higher in nonsurvivors than in survivors, regardless of the presence of sepsis (Figure 2). SOFA scores remained elevated in survivors but decreased over time in survivors, irrespective of the presence of sepsis.

\section{Discussion}

The main findings of our study were that (a) whatever the degree of organ failure at ICU admission, patients who exhibited an improvement or no change in organ function during the first 24 to 48 hours in the ICU had lower mortality rates than did those in whom organ function worsened; (b) in patients with single-organ failure during the ICU stay, hospital mortality was significantly greater in patients with sepsis than in those without; (c) patients with MOF had similar mortality rates, regardless of the presence of sepsis. 
Table 2 ICU and hospital mortality rates according to the number, type, and combinations of failed organs

\begin{tabular}{|c|c|c|c|c|c|c|}
\hline & \multicolumn{3}{|c|}{ On admission to the ICU } & \multicolumn{3}{|c|}{ At any time during ICU stay } \\
\hline & \multirow[t]{2}{*}{ Incidence (\%) } & \multicolumn{2}{|c|}{ Mortality (\%) } & \multirow[t]{2}{*}{ Incidence (\%) } & \multicolumn{2}{|c|}{ Mortality (\%) } \\
\hline & & $\overline{I C U}$ & Hospital & & $\overline{I C U}$ & Hospital \\
\hline \multicolumn{7}{|l|}{ Number of failed organs } \\
\hline 1 & $927(32)$ & 17 & 23 & $942(32)$ & 5 & 11 \\
\hline 2 & $524(18)$ & 28 & 37 & $677(23)$ & 24 & 33 \\
\hline 3 & $181(6)$ & 45 & 50 & $334(11)$ & 44 & 51 \\
\hline$>3$ & $43(1)$ & 58 & 70 & $157(5)$ & 73 & 79 \\
\hline \multicolumn{7}{|l|}{ Type of organ failure ${ }^{a}$} \\
\hline Cardiovascular & $717(24)$ & 31 & 39 & $993(34)$ & 35 & 41 \\
\hline Respiratory & $653(22)$ & 27 & 33 & $1,258(43)$ & 29 & 36 \\
\hline CNS & $601(21)$ & 32 & 39 & $757(26)$ & 38 & 45 \\
\hline Renal & $513(18)$ & 26 & 35 & $1,058(36)$ & 28 & 36 \\
\hline Coagulation & $130(18)$ & 36 & 45 & $290(10)$ & 44 & 54 \\
\hline Hepatic & $82(3)$ & 33 & 40 & $165(6)$ & 38 & 45 \\
\hline \multicolumn{7}{|l|}{ Combinations of two organ failures } \\
\hline Respiratory + cardiovascular & $274(9)$ & 39 & 46 & $726(25)$ & 39 & 46 \\
\hline Respiratory + renal & $120(4)$ & 42 & 49 & $543(19)$ & 41 & 48 \\
\hline Respiratory + CNS & $197(7)$ & 38 & 47 & $488(17)$ & 43 & 50 \\
\hline Hepatic + renal & $24(1)$ & 38 & 46 & $98(3)$ & 47 & 51 \\
\hline Respiratory + hepatic & $22(1)$ & 50 & 50 & $109(4)$ & 47 & 53 \\
\hline Renal + cardiovascular & $24(1)$ & 38 & 46 & $481(16)$ & 47 & 55 \\
\hline CNS + cardiovascular & $220(8)$ & 39 & 48 & $390(13)$ & 50 & 55 \\
\hline CNS + renal & $109(4)$ & 39 & 51 & $308(11)$ & 49 & 57 \\
\hline Hepatic + cardiovascular & $29(1)$ & 48 & 52 & $97(3)$ & 55 & 59 \\
\hline Respiratory + coagulation & $34(1)$ & 47 & 53 & $203(7)$ & 53 & 63 \\
\hline Coagulation + cardiovascular & $51(2)$ & 47 & 59 & $201(7)$ & 56 & 65 \\
\hline Coagulation + renal & $25(1)$ & 52 & 68 & $159(5)$ & 59 & 67 \\
\hline Coagulation + hepatic & $15(1)$ & 67 & 80 & $64(2)$ & 63 & 70 \\
\hline Hepatic + CNS & $29(1)$ & 58 & 67 & $97(3)$ & 66 & 71 \\
\hline Coagulation + CNS & $23(1)$ & 65 & 74 & $113(4)$ & 69 & 79 \\
\hline
\end{tabular}

${ }^{\mathrm{a}}$ Alone or in combination with other organs.

The association between early improvement in organ function and favorable prognosis has been reported in several other studies $[8,15,16]$. In 287 patients with severe sepsis, Russell et al. [15] reported that worsening of organ function over the first 3 days after the onset of sepsis syndrome was associated with higher 30 -day mortality rates than was improvement or no change in organ function. In a study of 1,036 patients with severe sepsis, Levy et al. [16] also reported that early changes (baseline to day 1 ) in organ function were closely related to outcome. Interestingly, we found that the evolution of organ function on the second day in the ICU was associated with outcome, irrespective of the degree of organ function on admission to the ICU. These observations may help to identify patients in whom continuing therapy is likely to be futile [17], or to define patients who may benefit from a change in therapeutic strategy (for example, another surgical intervention, a change in antibiotic therapy, or moreintensive vasoactive support).
We found that the time required to achieve the highest degree of organ dysfunction/failure was shorter in survivors than in non-survivors. However, no specific pattern of organ failure was related to the presence of sepsis in our patients. Dulhunty et al. [18] reported that CNS dysfunction was more commonly present in patients with systemic inflammatory response syndrome (SIRS) but no infection and was associated more commonly with death in these patients than in those with sepsis. However, the assessment of neurologic failure using the GCS may be confounded by the frequent use of sedative agents in critically ill patients.

Several studies $[3,6,16,19]$ have investigated the epidemiology and outcome of sepsis-associated organ dysfunction/failure; however, studies in the nonsepsis population are scarce $[4,18]$. Dulhunty et al. $[18]$ investigated the time course of organ dysfunction and outcome in patients with severe sepsis and patients with severe noninfectious SIRS, but excluded all other patients, 


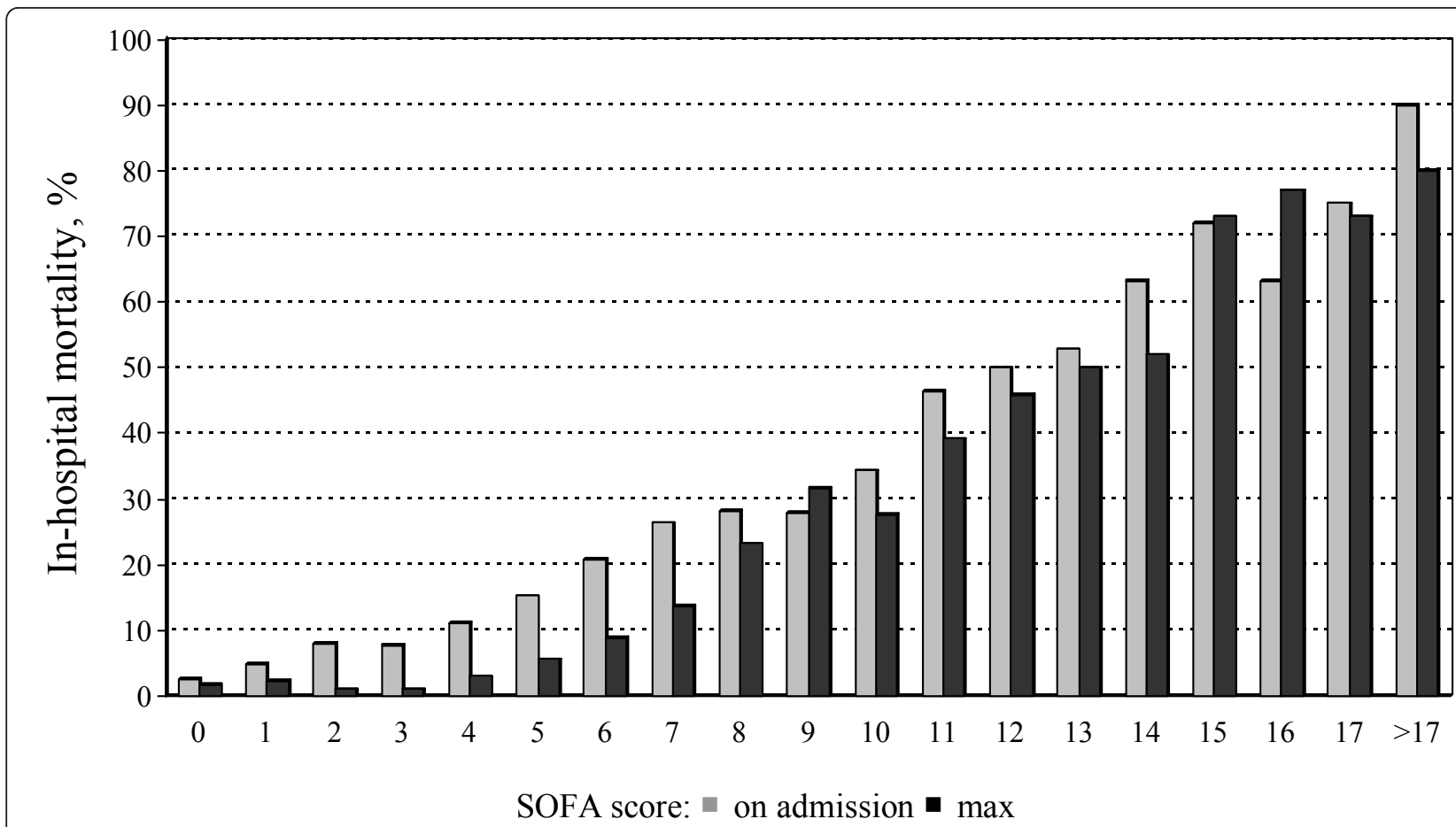

Figure 1 Hospital mortality rates according to SOFA score on admission (gray columns) and the maximum SOFA score (black columns).

which may explain the higher ICU mortality rate of $25 \%$ in their noninfected population, compared with the $20 \%$ in our study. In our study, hospital mortality from single-organ failure during the ICU stay was greater in patients with sepsis than in those who never had sepsis; interestingly, mortality rates from MOF were similar, regardless of the presence of sepsis. In their large cohort of ICU patients in Australasia, Dulhunty et al. [18] reported similar findings.

Interestingly, the highest hospital mortality rates were observed in patients with failure of the hepatic or coagulation systems. Because disturbances of coagulation parameters are closely related with liver failure, this study highlights the enormous importance of liver function on the outcome of ICU patients. Umegaki et al. [20] also recently reported that hepatic dysfunction compared with other organ dysfunction was associated with the highest mortality rates in a study including 4,196 patients with severe sepsis.

A key strength of our study is the large database of patients and its multicenter, pan-European nature. The SOAP study was performed several years ago, but organ-dysfunction patterns are likely to change slowly over time, so these data are still relevant. Nevertheless, our study has some limitations. First, participation was on a voluntary basis. Second, our results can be extrapolated only to ICUs with a similar case-mix. Third, other factors, which were not considered in our report, may influence the outcome of MOF, including comorbidities, severity of illness, and local practice. We also did not discriminate between acute and chronic organ failure in our analysis.

\section{Conclusions}

Although sepsis patients have worse outcomes than do nonsepsis patients, the differences are primarily in patients with only one organ failure, as the mortality in MOF is very high, regardless of the presence of sepsis. In all patients (with or without sepsis), changes in organ function during the first 24 to 48 hours after ICU admission can determine outcome, irrespective of the baseline degree of organ dysfunction. These patterns of organ failure and their relation to outcome may be useful in prognostication and, hence, in risk stratification of critically ill patients, including in the setting of clinical trials.

\section{Key messages}

- Whatever the degree of organ failure on admission to the ICU, patients who exhibited an improvement in organ function during the first 24 to 48 hours in the ICU had lower mortality rates than did the other patients.

- Higher mortality rates in sepsis compared with nonsepsis patients are primarily the result of higher mortality associated with single rather than multiorgan failure. 


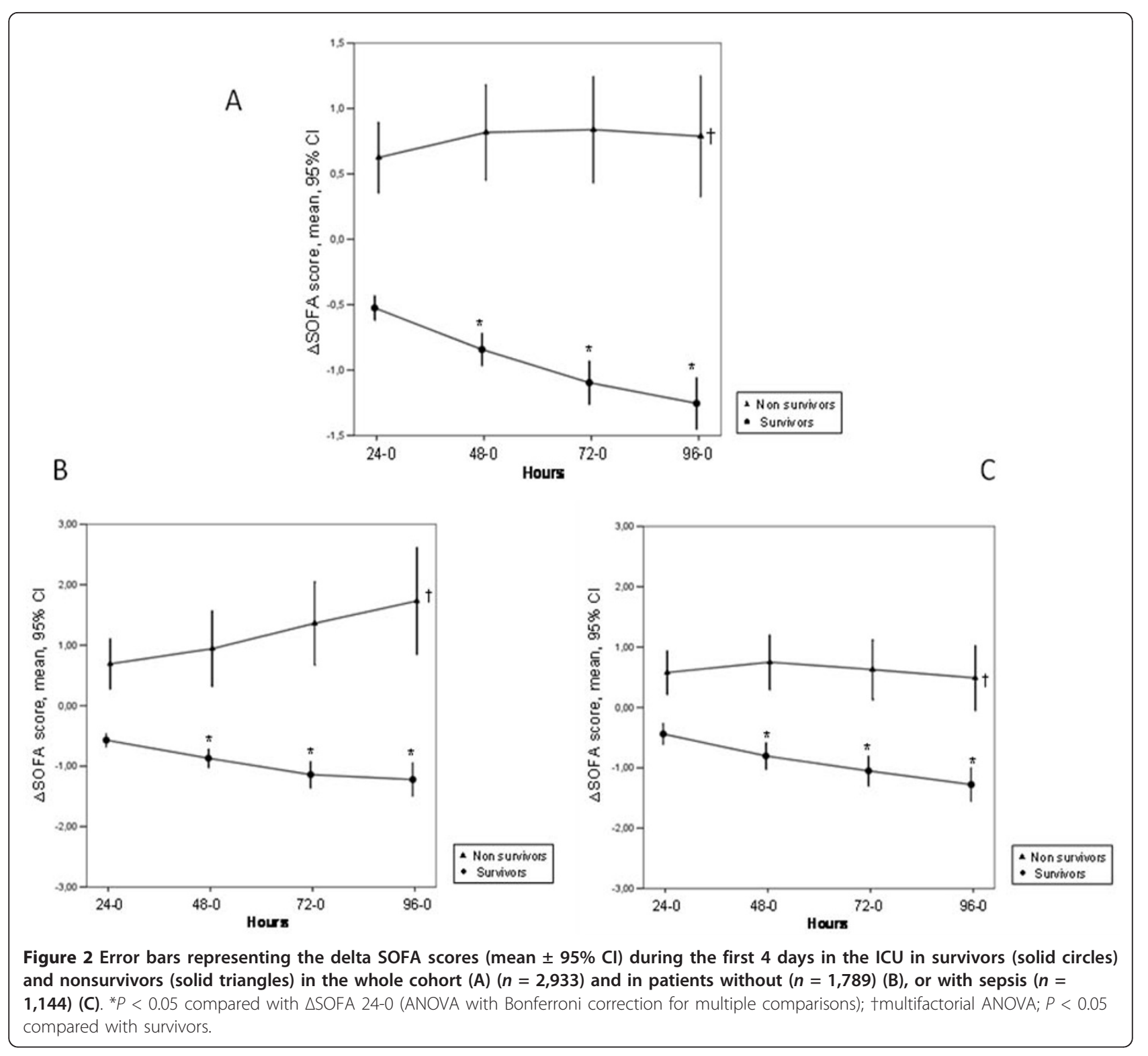

Table 3 Incidence of organ failure according to the presence of sepsis

\begin{tabular}{llll}
\hline & No sepsis $(\boldsymbol{n}=\mathbf{1 , 7 8 9})$ & Sepsis within $\mathbf{4 8}$ hours $(\boldsymbol{n}=\mathbf{8 6 5})$ & Sepsis after 48 hours $(\boldsymbol{n}=\mathbf{2 7 9})$ \\
\hline Organ failure on admission to the ICU & & & \\
\hline Number of failing organs, median (IQ) & $0(0-1)$ & $1(0-2)^{\mathrm{a}}$ & $1(0-2)^{\mathrm{a}}$ \\
Any organ failure, $n(\%)$ & $874(49)$ & $607(70)^{\mathrm{a}}$ & $194(70)^{\mathrm{a}}$ \\
1 & $563(32)$ & $271(31)$ & $93(33)$ \\
2 & $228(13)$ & $219(25)^{\mathrm{a}}$ & $77(28)^{\mathrm{a}}$ \\
3 & $72(4)$ & $87(10)^{\mathrm{a}}$ & $22(8)^{\mathrm{a}}$ \\
$>3$ & $11(1)$ & $30(3)^{\mathrm{b}}$ & $2(1)$ \\
Type of organ failure & & & $77(28)^{\mathrm{a}}$ \\
Respiratory & $320(18)$ & $256(30)^{\mathrm{a}}$ & $85(31)^{\mathrm{a}}$ \\
CNS & $317(18)$ & $199(23)^{\mathrm{a}}$ & $91(33)^{\mathrm{a}}$ \\
Cardiovascular & $306(17)$ & $320(37)^{\mathrm{a}}$ & $45(16)$ \\
Renal & $258(14)$ & $210(24)^{\mathrm{a}}$ &
\end{tabular}


Table 3 Incidence of organ failure according to the presence of sepsis (Continued)

\begin{tabular}{|c|c|c|c|}
\hline Coagulation & $49(3)$ & $69(8)^{a}$ & $12(4)$ \\
\hline Hepatic & $30(2)$ & $41(5)^{\mathrm{a}}$ & $11(4)^{b}$ \\
\hline \multicolumn{4}{|l|}{ Organ failure at any time during ICU stay } \\
\hline Number of failing organs, median (IQ) & $1(0-2)$ & $2(1-3)$ & $2(1-3)$ \\
\hline Any organ failure, $n(\%)$ & $1,120(63)$ & $732(85)^{a}$ & $258(92)^{a}$ \\
\hline 1 & $652(36)$ & $230(27)^{a}$ & $60(22)^{a}$ \\
\hline 2 & $307(17)$ & $253(29)^{a}$ & $117(42)^{a}$ \\
\hline 3 & $121(7)$ & $158(18)^{a}$ & $55(20)^{a}$ \\
\hline$>3$ & $40(2)$ & $98(11)^{a}$ & $26(9)^{a}$ \\
\hline \multicolumn{4}{|l|}{ Type of organ failure } \\
\hline Renal & $559(31)$ & $386(45)^{a}$ & $113(41)^{a}$ \\
\hline Respiratory & $514(29)$ & $528(61)^{\mathrm{a}}$ & $216(77)^{a}$ \\
\hline Cardiovascular & $406(23)$ & $432(50)^{a}$ & $155(56)^{a}$ \\
\hline CNS & $368(21)$ & $270(31)^{a}$ & $119(43)^{a}$ \\
\hline Coagulation & $102(6)$ & $143(17)^{\mathrm{a}}$ & $45(16)^{a}$ \\
\hline Hepatic & $49(3)$ & $84(10)^{a}$ & $32(12)^{a}$ \\
\hline
\end{tabular}

CNS, central nervous system; IQ, interquartile range. ${ }^{b} P<0.05$; ${ }^{a} P<0.01$ compared with patients without sepsis (pairwise comparisons with Bonferroni correction for multiple comparisons).

Table 4 ICU and hospital mortality rates according to the number and type of failed organs and the presence of sepsis

\begin{tabular}{|c|c|c|c|c|c|c|}
\hline & \multicolumn{3}{|c|}{ ICU mortality (\%) } & \multicolumn{3}{|c|}{ Hospital mortality } \\
\hline & $\begin{array}{l}\text { No sepsis } n \\
=1,789\end{array}$ & $\begin{array}{l}\text { Sepsis within } 48 \\
\text { hours } n=865\end{array}$ & $\begin{array}{l}\text { Sepsis after } 48 \\
\text { hours } n=279\end{array}$ & $\begin{array}{l}\text { No sepsis } n \\
=1,789\end{array}$ & $\begin{array}{l}\text { Sepsis within } 48 \\
\text { hours } n=865\end{array}$ & $\begin{array}{l}\text { Sepsis after } 48 \\
\text { hours } n=279\end{array}$ \\
\hline \multicolumn{7}{|c|}{ On admission to the ICU } \\
\hline Any organ failure & 20 & $30^{a}$ & $30^{\mathrm{a}}$ & 25 & $40^{\mathrm{a}}$ & $37^{a}$ \\
\hline 1 & 13 & $20^{\mathrm{a}}$ & $30^{\mathrm{a}}$ & 18 & $30^{\mathrm{a}}$ & $36^{a}$ \\
\hline 2 & 25 & 30 & 29 & 33 & $41^{\mathrm{a}}$ & $38^{\mathrm{a}}$ \\
\hline 3 & 44 & 48 & 32 & 47 & 56 & 36 \\
\hline$>3$ & 55 & 60 & 50 & 64 & 73 & 50 \\
\hline \multicolumn{7}{|l|}{$\begin{array}{l}\text { Type of organ } \\
\text { failure }\end{array}$} \\
\hline Respiratory & 10 & $34^{a}$ & $31^{\mathrm{a}}$ & 25 & $44^{\mathrm{a}}$ & $36^{\mathrm{a}}$ \\
\hline CNS & 34 & 32 & $27^{\mathrm{a}}$ & 38 & $42^{b}$ & $36^{a}$ \\
\hline Cardiovascular & 25 & $38^{\mathrm{a}}$ & $28^{\mathrm{b}}$ & 31 & $48^{\mathrm{a}}$ & $33^{\mathrm{a}}$ \\
\hline Renal & 20 & $32^{\mathrm{a}}$ & $31^{\mathrm{a}}$ & 26 & $44^{\mathrm{a}}$ & $42^{\mathrm{a}}$ \\
\hline Coagulation & 22 & $46^{a}$ & $33^{b}$ & 27 & $58^{\mathrm{a}}$ & $50^{\mathrm{b}}$ \\
\hline Hepatic & 20 & $34^{\mathrm{a}}$ & $64^{\mathrm{a}}$ & 28 & $42^{\mathrm{a}}$ & $64^{\mathrm{a}}$ \\
\hline \multicolumn{7}{|c|}{ At any time during the ICU stay } \\
\hline Any organ failure & 17 & $28^{\mathrm{a}}$ & $30^{\mathrm{a}}$ & 22 & $38^{\mathrm{a}}$ & $37^{a}$ \\
\hline 1 & 5 & 6 & 7 & 9 & $16^{\mathrm{a}}$ & $13^{\mathrm{a}}$ \\
\hline 2 & 24 & 23 & 27 & 32 & 34 & 34 \\
\hline 3 & 47 & 43 & 42 & 50 & 52 & 51 \\
\hline$>3$ & 76 & 71 & 69 & 76 & 89 & 77 \\
\hline \multicolumn{7}{|l|}{$\begin{array}{l}\text { Type of organ } \\
\text { failure }\end{array}$} \\
\hline Renal & 20 & $38^{\mathrm{a}}$ & $41^{a}$ & 26 & $50^{\mathrm{a}}$ & $50^{\mathrm{a}}$ \\
\hline Respiratory & 24 & $32^{\mathrm{a}}$ & $32^{\mathrm{a}}$ & 28 & $41^{a}$ & $40^{\mathrm{a}}$ \\
\hline Cardiovascular & 29 & $40^{\mathrm{a}}$ & $37^{\mathrm{a}}$ & 33 & $49^{a}$ & $42^{\mathrm{a}}$ \\
\hline CNS & 36 & $40^{\mathrm{a}}$ & $39^{a}$ & 40 & $50^{\mathrm{a}}$ & $46^{\mathrm{a}}$ \\
\hline Coagulation & 33 & $49^{\mathrm{a}}$ & $53^{\mathrm{a}}$ & 41 & $60^{\mathrm{a}}$ & $64^{\mathrm{a}}$ \\
\hline Hepatic & 27 & $42^{\mathrm{a}}$ & $47^{\mathrm{a}}$ & 33 & $49^{\mathrm{a}}$ & $50^{\mathrm{a}}$ \\
\hline
\end{tabular}

CNS, central nervous system; $\mathrm{IQ}$, interquartile range. ${ }^{\mathrm{b}} P<0.05 ;{ }^{\mathrm{a}} P<0.01$ compared with patients without sepsis (pairwise comparisons with Bonferroni correction for multiple comparisons). 
- Mortality rates in patients with multiorgan failure are high, irrespective of the presence of sepsis.

- Improved knowledge of patterns of organ failure and their relation to outcome may be useful in prognostication and, hence, in risk stratification of critically ill patients.

\section{Abbreviations}

CNS: central nervous system; GCS: Glasgow Coma Scale; ICU: intensive care unit; MOF: multiple organ failure; SAPS: simplified acute physiology score; SIRS: systemic inflammatory response syndrome; SOFA: sequential organ failure assessment.

\section{Acknowledgements}

The SOAP study was supported by an unlimited grant from Abbott, Baxter, Eli Lilly, GlaxoSmithKline, and NovoNordisk. These companies had no involvement at any stage of the study design, in the collection and analysis of data, in writing the manuscript, or in the decision to submit for publication. We also acknowledge the important role of all the participating centers (listed by country alphabetically): Austria: University Hospital of Vienna (G. Delle Karth); LKH Steyr (V. Draxler); LKH-Deutschlandsberg (G. Filzwieser); Otto Wagner Spital of Vienna (W. Heindl); Krems of Donau (G. Kellner, T. Bauer); Barmherzige Bruede of Linz (K. Lenz); KH Floridsdorf of Vienna (E. Rossmann); University Hospital of Innsbruck (C. Wiedermann); Belgium: CHU of Charleroi (P. Biston); Hôpitaux Iris Sud of Brussels (D. Chochrad); Clinique Europe Site St Michel of Brussels (V. Collin); C.H.U. of Liège (P. Damas); University Hospital Ghent (J. Decruyenaere, E. Hoste); CHU Brugmann of Brussels (J. Devriendt); Centre Hospitalier Jolimont-Lobbes of Haine St Paul (B. Espeel); CHR Citadelle of Liege (V. Fraipont); UCL MontGodinne of Yvoir (E. Installe); ACZA Campus Stuivenberg (M. Malbrain); OLV Ziekenhuis Aalst (G. Nollet); RHMS Ath-Baudour-Tournai (J.C. Preiser); AZ St Augustinus of Wilrijk (J. Raemaekers); CHU Saint-Pierre of Brussels (A. Roman); Cliniques du Sud-Luxembourg of Arlon (M. Simon); Academic Hospital Vrije Universiteit Brussels ( $H$. Spapen); AZ Sint-Blasius of Dendermonde (W. Swinnen); Clinique Notre-Dame of Tournai (F. Vallot); Erasme University Hospital of Brussels (J.L. Vincent); Czech Republic: University Hospital of Plzen (I. Chytra); U SV.Anny of Brno (L. Dadak); Klaudians of Mlada Boleslav (I. Herold); General Faculty Hospital of Prague (F. Polak); City Hospital of Ostrava (M. Sterba); Denmark: Gentofte Hospital, University of Copenhagen (M. Bestle); Rigshospitalet of Copenhagen (K. Espersen); Amager Hospital of Copenhagen ( $\mathrm{H}$. Guldager); Rigshospitalet, University of Copenhagen (K-L. Welling); Finland: Aland Central Hospital of Mariehamn (D. Nyman); Kuopio University Hospital (E. Ruokonen); Seinajoki Central Hospital (K. Saarinen); France: Raymond Poincare of Garches (D. Annane); Institut Gustave Roussy of Villejuif (P. Catogni); Jacques Monod of Le Havre (G. Colas); CH Victor Jousselin of Dreux (F. Coulomb); Hôpital St Joseph \& St Luc of Lyon (R. Dorne); Saint Joseph of Paris (M. Garrouste); Hôpital Pasteur of Nice (C. Isetta); CHU Brabois of Vandoeuvre Les Nancy (J. Larché); Saint Louis of Paris (J-R. LeGall); CHU de Grenoble (H. Lessire); CHU Pontchaillou of Rennes (Y. Malledant); Hôpital des Hauts Clos of Troyes (P. Mateu); CHU of Amiens (M. Ossart); Hôpital Lariboisière of Paris (D. Payen); CHD Félix Gyuon of Saint Denis La Reunion (P. Schlossmacher); Hôpital Bichat of Paris (J-F. Timsit); Hôpital Saint Andre of Bordeaux (S. Winnock); Hôpital Victor Dupouy of Argentueil (J-P. Sollet); CH Auch (L. Mallet); CHU Nancy-Brabois of Vandoeuvre (P. Maurer); CH William Morey of Chalon (J-M. Sab); Victor Dupouy of Argenteuil (J-P. Sollet); Germany: University Hospital Heidelberg (G. Aykut); Friedrich Schiller University Jena (F. Brunkhorst); University Clinic Hamburg-Eppendorf (A. Nierhaus); University Hospital Mainz (M. Lauterbach); University Hospital Carl Gustav Carus of Dresden (M. Ragaller); Hans Sushemihl Krankenhaus of Emden (R. Gatz); Vivantes-Klinikum Neukoelln of Berlin (H. Gerlach); University Hospital RWTH Aachen (D. Henzler); Kreisklinik Langen-Seligenstadt (H-B Hopf); GKH Bonn (H. Hueneburg); Zentralklinik Bad Berka (W. Karzai); Neuwerk of Moenchengladbach (A. Keller); Philipps University of Marburg (U. Kuhlmann); University Hospital Regensburg (J. Langgartner); ZKH Links der Weser of Bremen (C. Manhold); University Hospital of Dresden (M. Ragaller); Universtiy of Wuerzburg (B. Reith); Hannover Medical School (T. Schuerholz); Universitätsklinikum Charité Campus Mitte of Berlin (C. Spies); Bethanien Hospital of Moers (R.
Stögbauer); KhgmbH Schongau (J. Unterburger); Greece: Thriassio Hospital of Athens (P-M. Clouva-Molyvdas); Sismanoglion General Hospital of Athens (G. Giokas); KAT General Hospital of Athens (E. Ioannidou); G. Papanikolaou General Hospital of Thessaloniki (A. Lahana); Agios Demetrios of Thessaloniki (A. Liolios); Onassis Cardiac Surgery Center of Athens (K. Marathias); University Hospital of loannina (G. Nakos); Tzanio Hospital of Athens (A. Tasiou); Athens General Hospital Gennimatas (H. Tsangaris); Hungary: Peterfy Hospital of Budapest (P. Tamasi); Ireland: Mater Hospital of Dublin (B. Marsh); Beaumont Hospital of Dublin (M. Power); Israel: Hadassah Hebrew University Medical Center (C. Sprung); Italy: Azienda Ospedaliera Senese o Siena (B. Biagioli); S. Martino of Genova (F. Bobbio Pallavicini); Azienda Ospedaliera S. Gerardo dei Tintori of Monza (A. Pesenti); Osp Regionale of Saronno (C. Capra); Ospedale Maggiore - University A. Avogadro of Novara (F. Della Corte); Osp. Molinette of Torino (P. P. Donadio); A.O. Umberto I Ancona, Rianimazione Clinica (A. Donati); Azienda Ospedaliera Universitaria Policlinico of Palermo (A. Giarratano); San Giovanni Di Dio of Florence (T. Giorgio); H San Raffaele IRCCS of Milano (D. Giudici); Ospedale Di Busto Arsizio (S. Greco); Civile Di Massa (A. Guadagnucci); San Paolo of Milano (G. Lapichino); S.Giovanni Bosco Torino (S. Livigni); Osp. San Giovanni of Sesto (G. Moise); S Camillo of Roma (G. Nardi); Vittorio Emanuele of Catania (E. Panascia); Hospital of Piacenza (M. Pizzamiglio); Universita di Torino-Ospedale S. Giovanni Battista (V. M. Ranieri); Policlinico Le Scotte of Siena (R. Rosi); Ospedale Maggiore Policlinico IRCCS of Milano (A. Sicignano); A. Uboldo of Cernusco Sul Naviglio (M. Solca); P.O. Civile Carrara of Massa (G. Vignali); San Giovanni of Roma (I. Volpe Rinonapoli); Netherlands: Boven IJ Ziekenhuis of Amsterdam (M. Barnas); UMC St Radboud of Nijmegen (E.E. De Bel); Academic Medical Center of Amsterdam (A-C. De Pont); VUMC of Amsterdam (J. Groeneveld); Groningen University Hospital (M Nijsten); Waterlandziekenhuis of Purmerend ( $\mathrm{L}$ Sie); OLVG of Amsterdam (D. F. Zandstra); Norway: Sentralsjukehuset i Rogaland of Stavanger (S. Harboe); Sykehuset Østfold of Fredrikstad (S. Lindén); Aker University Hospital of Oslo (R. Z. Lovstad); Ulleval University Hospitalof Oslo (H. Moen); Akershus University Hospital of Nordbyhagen (N. Smith-Erichsen); Poland: Paediatric University Hospital of Lodz (A. Piotrowski); Central Clinic Hospital SLAM of Katowice (E. Karpel); Portugal: Garcia de Orta of Almada (E. Almeida); Hospital de St. António dos Capuchos of Lisboa (R. Moreno); Hospital de Santa Maria of Lisboa (A. Pais-De-Lacerda); Hospital S.Joao of Porto (J. A. Paiva); Fernado Fonseca of Masama (I. Serra); São Teotonio Viseu (A. Pimentel); Romania: Inst of Cardiovascular Diseases of Bucharest (D. Filipescu); Serbia and Montenegro: Military Medical Academy of Belgrade (K. Jovanovic); Slovakia: SUSCH of Bratislava (P. Malik); Slovenia: General Hospital of Novo Mesto (K. Lucka); General Hospital of Celje (G. Voga); Spain: Hospital Universitario Rio Hortega of Valladolid (C. Aldecoa Alvarez-Santullano); Sabadell Hospital (A. Artigas); Hospital Clinic of Barcelona (E. Zavala, A. Escorsell, J. Nicolas); Virgen del Camino of Pamplona (J. J. Izura Cea); Virgen de la Salud of Toledo (L. Marina); 12 de Octubre of Madrid (J. Montejo); Gregorio Maranon of Madrid (E. Palencia); General Universitario de Elche (F. Santos); Puerta del Mar of Cadiz (R. Sierra-Camerino); Fundación Jiménez Díaz of Madrid (F. Sipmann); Hospital Clinic of Barcelona (E. Zavala); Sweden: Central Hospital of Kristianstad (K. Brodersen); Stockholm Soder Hospital (J. Haggqvist); Sunderby Hospital of Luleå (D. Hermansson); Huddinge University Hospital of Stockholm (H. Hjelmqvist); Switzerland: Kantonsspital Luzern (K. Heer); Hirslanden Klinik Beau-Site of Bern (G. Loderer); University Hospital of Zurich (M. Maggiorini); Hôpital de la ville of La Chaux-de-Fonds (H. Zender); United Kingdom: Edinburgh Western General Hospital (P. Andrews); Peterborough Hospitals NHS Trust of Peterborough (B. Appadu); University Hospital Lewisham, London (C. Barrera Groba); Bristol Royal Infirmary (J. Bewley); Queen Elizabeth Hospital Kings Lynn (K. Burchett); Milton Keynes General (P. Chambers); Homerton University Hospital of London (J. Coakley); Charing Cross Hospital of London (D. Doberenz); North Staffordshire Hospital of Stoke On Trent (N. Eastwood); Antrim Area Hospital (A. Ferguson); Royal Berkshire Hospital of Reading (J. Fielden); The James Cook University Hospital of Middlesbrough (J. Gedney); Addenbrookes of Cambridge (K. Gunning); Rotherham DGH (D. Harling); St.Helier of Carshalton (S. Jankowski); Southport \& Formby (D. Jayson); Freeman of Newcastle Upon Tyne (A. Kilner); University Hospital of North Tees at Stockton on Tees (V. Krishna-Kumar); St. Thomas Hospital of London (K. Lei); Royal Infirmary of Edinburgh (S. Mackenzie); Derriford of Plymouth (P. Macnaughton); Royal Liverpool University Hospital (G. Marx); Stirling Royal Infirmary (C. McCulloch); University Hospital of Wales, Cardiff (P. Morgan); St George's Hospital of London (A. Rhodes); Gloucestershire Royal Hospital (C. Roberts); St Peters of 
Chertsey (M. Russell); James Paget Hospital of Great Yarmouth (D. TupperCarey, M. Wright); Kettering General Hospital (L. Twohey); Burnley DGH (J. Watts); Northampton General Hospital (R. Webster); Dumfries Royal Infirmary (D. Williams)

\section{Author details}

${ }^{1}$ Department of Anesthesiology and Intensive Care, Friedrich-SchillerUniversity, Erlanger Allee 103, 07743 Jena, Germany. ${ }^{2}$ Division of Critical Care Medicine, Department of Internal Medicine, Medical School-FUNFARME and Hospital de Base, São José do Rio Preto, São Paulo, Brazil. ${ }^{3}$ Dunidade de Cuidados Intensivos Neurocriticos, Hospital de São José, Centro Hospitalar de Lisboa Central, E.P.E., Rua José António Serrano, 1150-199 Lisbon, Portugal. ${ }^{4}$ Department of Anesthesia, Intensive Care Medicine, and Pain Management, Vivantes-Klinikum Neukölln, Rudower Strasse 48, D-12313 Berlin, Germany. ${ }^{5}$ Department of Anesthesia and Critical Care, Ospedale S. Giovanni BattistaMolinette, corso Dogliotti 14, 10126, University of Turin, Turin, Italy. ${ }^{6}$ Intensive Care Unit, Henry Dunant Hospital, Department of Medicine, Athens, Greece. ${ }^{7}$ Department of Intensive Care, Erasme Hospital, Université Libre de Bruxelles, Brussels, Route de Lennik 808, 1070 Brussels, Belgium.

\section{Authors' contributions}

$J L V$ conceived the initial SOAP study. RM, HG, VMR, YS, and JLV participated in the design and coordination of the SOAP study. YS performed the statistical analyses. SL, YS, and JLV drafted the present manuscript. RM, VMR, $A G$, YS revised the draft. All authors read and approved the final manuscript.

\section{Competing interests}

The authors declare that they have no competing interests.

Received: 22 May 2012 Revised: 29 July 2012

Accepted: 20 August 2012 Published: 16 November 2012

\section{References}

1. Seely AJ, Christou NV: Multiple organ dysfunction syndrome: exploring the paradigm of complex nonlinear systems. Crit Care Med 2000, 28:2193-2200

2. Vincent JL, Sakr Y, Sprung CL, Ranieri VM, Reinhart K, Gerlach H, Moreno R, Carlet J, Le Gall JR, Payen D: Sepsis in European intensive care units: results of the SOAP study. Crit Care Med 2006, 34:344-353.

3. Angus DC, Linde-Zwirble WT, Lidicker J, Clermont G, Carcillo J, Pinsky MR: Epidemiology of severe sepsis in the United States: analysis of incidence, outcome, and associated costs of care. Crit Care Med 2001, 29:1303-1310.

4. Afessa B, Green B, Delke I, Koch K: Systemic inflammatory response syndrome, organ failure, and outcome in critically ill obstetric patients treated in an ICU. Chest 2001, 120:1271-1277.

5. Martin GS, Mannino DM, Eaton S, Moss M: The epidemiology of sepsis in the United States from 1979 through 2000. N Engl J Med 2003, 348:1546-1554.

6. Vincent JL, Moreno R, Takala J, Willatts S, De Mendonca A, Bruining H, Reinhart CK, Suter PM, Thijs LG: The SOFA (Sepsis-related Organ Failure Assessment) score to describe organ dysfunction/failure, On behalf of the Working Group on Sepsis-Related Problems of the European Society of Intensive Care Medicine. Intensive Care Med 1996, 22:707-710.

7. Vincent IL, De Mendonca A, Cantraine F, Moreno R, Takala J, Suter PM, Sprung CL, Colardyn F, Blecher S: Use of the SOFA score to assess the incidence of organ dysfunction/failure in intensive care units: results of a multicenter, prospective study; Working group on "sepsis-related problems" of the European Society of Intensive Care Medicine. Crit Care Med 1998, 26:1793-1800.

8. Ferreira FL, Bota DP, Bross A, Melot C, Vincent IL: Serial evaluation of the SOFA score to predict outcome in critically ill patients. JAMA 2001, 286:1754-1758.

9. Antonelli M, Moreno R, Vincent JL, Sprung CL, Mendoca A, Passariello M, Riccioni L, Osborn J: Application of SOFA score to trauma patients: Sequential Organ Failure Assessment. Intensive Care Med 1999, 25:389-394.

10. Moreno R, Vincent JL, Matos R, Mendonca A, Cantraine F, Thijs L, Takala J, Sprung C, Antonelli M, Bruining $H$, Willatts $S$ : The use of maximum SOFA score to quantify organ dysfunction/failure in intensive care: results of a prospective, multicentre study; Working Group on Sepsis related Problems of the ESICM. Intensive Care Med 1999, 25:686-696.
11. Cruz DN, Antonelli M, Fumagalli R, Foltran F, Brienza N, Donati A, Malcangi V, Petrini F, Volta G, Bobbio Pallavicini FM, Rottoli F, Giunta F, Ronco C: Early use of polymyxin B hemoperfusion in abdominal septic shock: the EUPHAS randomized controlled trial. JAMA 2009, 301:2445-2452.

12. Jabre $P$, Combes $X$, Lapostolle $F$, Dhaouadi $M$, Ricard-Hibon A, Vivien $B$, Bertrand L, Beltramini A, Gamand P, Albizzati S, Perdrizet D, Lebail G, Chollet-Xemard C, Maxime V, Brun-Buisson C, Lefrant JY, Bollaert PE, Megarbane B, Ricard JD, Anguel N, Vicaut E, Adnet F: Etomidate versus ketamine for rapid sequence intubation in acutely ill patients: a multicentre randomised controlled trial. Lancet 2009, 374:293-300.

13. Le Gall JR, Lemeshow S, Saulnier F: A new Simplified Acute Physiology Score (SAPS II) based on a European/North American multicenter study. JAMA 1993, 270:2957-2963.

14. Bone RC, Balk RA, Cerra FB, Dellinger RP, Fein AM, Knaus WA, Schein RM, Sibbald WJ: Definitions for sepsis and organ failure and guidelines for the use of innovative therapies in sepsis: the ACCP/SCCM Consensus Conference Committee, American College of Chest Physicians/Society of Critical Care Medicine. Chest 1992, 101:1644-1655.

15. Russell JA, Singer J, Bernard GR, Wheeler A, Fulkerson W, Hudson L, Schein R, Summer W, Wright P, Walley KR: Changing pattern of organ dysfunction in early human sepsis is related to mortality. Crit Care Med 2000, 28:3405-3411.

16. Levy MM, Macias WL, Vincent JL, Russell JA, Silva E, Trzaskoma B, Williams MD: Early changes in organ function predict eventual survival in severe sepsis. Crit Care Med 2005, 33:2194-2201.

17. Cabre L, Mancebo J, Solsona JF, Saura P, Gich I, Blanch L, Carrasco G, Martin MC: Multicenter study of the multiple organ dysfunction syndrome in intensive care units: the usefulness of Sequential Organ Failure Assessment scores in decision making. Intensive Care Med 2005, 31:927-933.

18. Dulhunty JM, Lipman J, Finfer S: Does severe non-infectious SIRS differ from severe sepsis? Results from a multi-centre Australian and New Zealand intensive care unit study. Intensive Care Med 2008, 34:1654-1661.

19. Guidet B, Aegerter P, Gauzit R, Meshaka P, Dreyfuss D: Incidence and impact of organ dysfunctions associated with sepsis. Chest 2005, 127:942-951

20. Umegaki T, Ikai H, Imanaka Y: The impact of acute organ dysfunction on patients' mortality with severe sepsis. J Anaesthesiol Clin Pharmacol 2011, 27:180-184.

doi:10.1186/cc11868

Cite this article as: Sakr et al:: Patterns and early evolution of organ failure in the intensive care unit and their relation to outcome. Critical Care 2012 16:R222.

\section{Submit your next manuscript to BioMed Central and take full advantage of:}

- Convenient online submission

- Thorough peer review

- No space constraints or color figure charges

- Immediate publication on acceptance

- Inclusion in PubMed, CAS, Scopus and Google Scholar

- Research which is freely available for redistribution

Submit your manuscript at www.biomedcentral.com/submit
C Biomed Central 